\title{
INFLUENCES OF SOME ENVIRONMENTAL FACTOR ON GROWTH AND SPORULATION OF SELECTED Trichoderma spp. SUBHASH CHANDRA ${ }^{1}$
}

P.G. Department of Botany, Sri Murli Manohar Town P.G. College, Ballia, Uttar Pradesh, India

\begin{abstract}
Two strains of Trichoderma harzianum and one strain each of Trichoderma viride, Trichoderma pseudokoningii and Trichoderma virens were evaluated at different temperature and $\mathrm{pH}$ on culture medium in the laboratory. The Trichoderma spp., grow and sporulate well at $25^{\circ} \mathrm{C}$. The best $\mathrm{pH}$ for growth and sporulation of all the strains were 5.5 and 6.5 respectively. Among the five strains tested, Trichoderma harzianum BHU was observed to sporulate and growth well in all the variable factors.
\end{abstract}

KEYWORDS: Trichoderma, Temperature, $\mathrm{pH}$, Growth and Sporulation

The species of the genus Trichoderma have been reported as most potential biocontrol agents against several soil-borne phytopathogens (Lewis and Papavizas, 1991; Haran et al., 1996a; 1996b; Elad, 2000; Hermosa et al., 2000; Kredics, et al., 2003; Joshi, et al., 2010) due to their ability to successfully antagonise other fungi. Establishment of the Trichoderma and other biocontrol agents in the soil ecosystem has greatly affected by numerous biotic and abiotic factors (Dandurand and Knudsen, 1993; Eastburn and Butler, 1988a, b; Hubbard et al., 1983; Knudsen and Bin 1990; Papavizas, 1985). These may have negative influence in the biocontrol efficacy of Trichoderma strains; therefore, it is important to collect information about the effects of environmental factors on the different activities of Trichoderma strains that possess biocontrol potential. It was reported that the production of metabolites from different show varying effects on pathogens (Henis, 1984; Rifai, 1969; Papavizas, 1985). The effect of environmental factors appeared to be a key parameter to manipulate for both growth and sporulation. Temperature is an important environmental factor affecting the disease suppression abilities of antagonistic microbes on the crops (Callan et al., 1990; Mathre and Johnston, 1995; Upadhyay et al., 1991), while the role of $\mathrm{pH}$ in conidial germination of Trichoderma species has already been reported (Baker, 1986; Papavizas 1985) has stated that different species of Trichoderma have their own ecological preferences. In the present paper the influences of environmental factor, temperature and $\mathrm{pH}$ on the growth and sporulation of selected Trichoderma spp., have been investigated.

\section{MATERIALS AND METHODS}

Source of Antagonist and Culture Medium

The pure culture of different strains of Trichoderma species were obtained from Laboratory of Applied Mycology and Plant Pathology, Department of Botany, BHU, Varanasi, where the culture were maintained from the collection centres of National Botanical Research Institute, Lucknow and Indian Institute of Vegetable Research, Varanasi. Local species/ strains of Trichoderma were isolated from soils of various locations from and the around BHU Campus, Varanasi, on the Trichoderma selective medium (TSM) (Askew and Laing, 1993).

\section{Effect of Temperature}

The effect of different temperature on growth and sporulation of the selected. Trichoderma spp., was observed at $25,30,35$ and $40^{\circ} \mathrm{C}$. A five mm diameter of agar block was cut from the margin of actively growing culture of each Trichoderma strains and placed centrally in Petri dish (9 cm, diameter) containing $20 \mathrm{ml}$ Potato Dextrose Agar (PDA) medium in triplicate and the plates were incubated at the above temperatures on BOD incubator. The observations were recorded after 4 days of incubation.

\section{Effect of $\mathbf{p H}$}

Different $\mathrm{pH}$ levels were adjusted in PDA medium at 3.5, 4.5, 5.5, 6.5 and 7.5 Erlenmeyer flasks $(500 \mathrm{ml})$ separately by adding $1 \mathrm{~N} \mathrm{HCl}$ or $1 \mathrm{~N} \mathrm{NaOH}$ solution as required. A $5 \mathrm{~mm}$ diameter of agar block was cut from the margin of actively growing culture of each Trichoderma strains and incubated centrally in Petri-dish 
contained $20 \mathrm{ml}$ of PDA medium. The observations were recorded after 4 days of inoculation.

\section{Sporulation Count}

The estimation of spore production of the selected Trichoderma spp., on different temperature and $\mathrm{pH}$ were done using the method described by El-Abyad et al., (1983). One square $\mathrm{cm}$. block of the different strains of Trichoderma spp., was cut from the margin of the actively growing colony and transferred separately to a test tube containing $2.5 \mathrm{ml}$ of sterile distilled water. The tube was shaken continuously for 5 minutes. The density of spores was then counted using a haemocytometer under high power (450) in a Nikon Trinocular Microscope (Model E-600).

\section{RESULTS AND DISCUSSION}

In the present investigation the effect of different environmental factors on the growth and sporulation of selected Trichoderma spp., were studied. Temperature and $\mathrm{pH}$ are probably the most important environmental parameters affecting the antagonistic activity of Trichoderma strains. Therefore, it was important to collect information on the effects of these factors on mycelial growth of the strains.
Mycelial growth of the Trichoderma spp., was recorded at the temperature range $25-40^{\circ} \mathrm{C}$. The optimal temperature for the growth was found to be $25^{\circ} \mathrm{C}$ for Trichoderma viride 1, Trichoderma pseudokoningii NBRI and Trichoderma virens $\mathrm{BHU}$, where as it was $30^{\circ} \mathrm{C}$ Trichoderma harzianum BHU and Trichoderma harzianum IVRI (Figure 1). Optimum temperatures for growth differ among species of Trichoderma (Danielson and Davey, 1973b; Komatsu, 1976). The result of the effect of $\mathrm{pH}$ (Figure 2) on mycelial growth reveals that both strains of Trichoderma harzianum possessed capability of growing at variable $\mathrm{pH}$. The examined strains were able to grow under a wide range of $\mathrm{pH}$ from 3.5 to 7.5 with maximal growth at $\mathrm{pH}$ 5.5. The result was in conformity with the observation of Jackson et al., (1991) who found that maximum biomass production of isolates was at $\mathrm{pH}$ values between 4.6 and 6.8. The objective of the study was to identify the Trichoderma species / strains that can grow most rapidly in laboratory test at a wide range of temperature and $\mathrm{pH}$ so that they may be used in fields having variable environmental conditions.

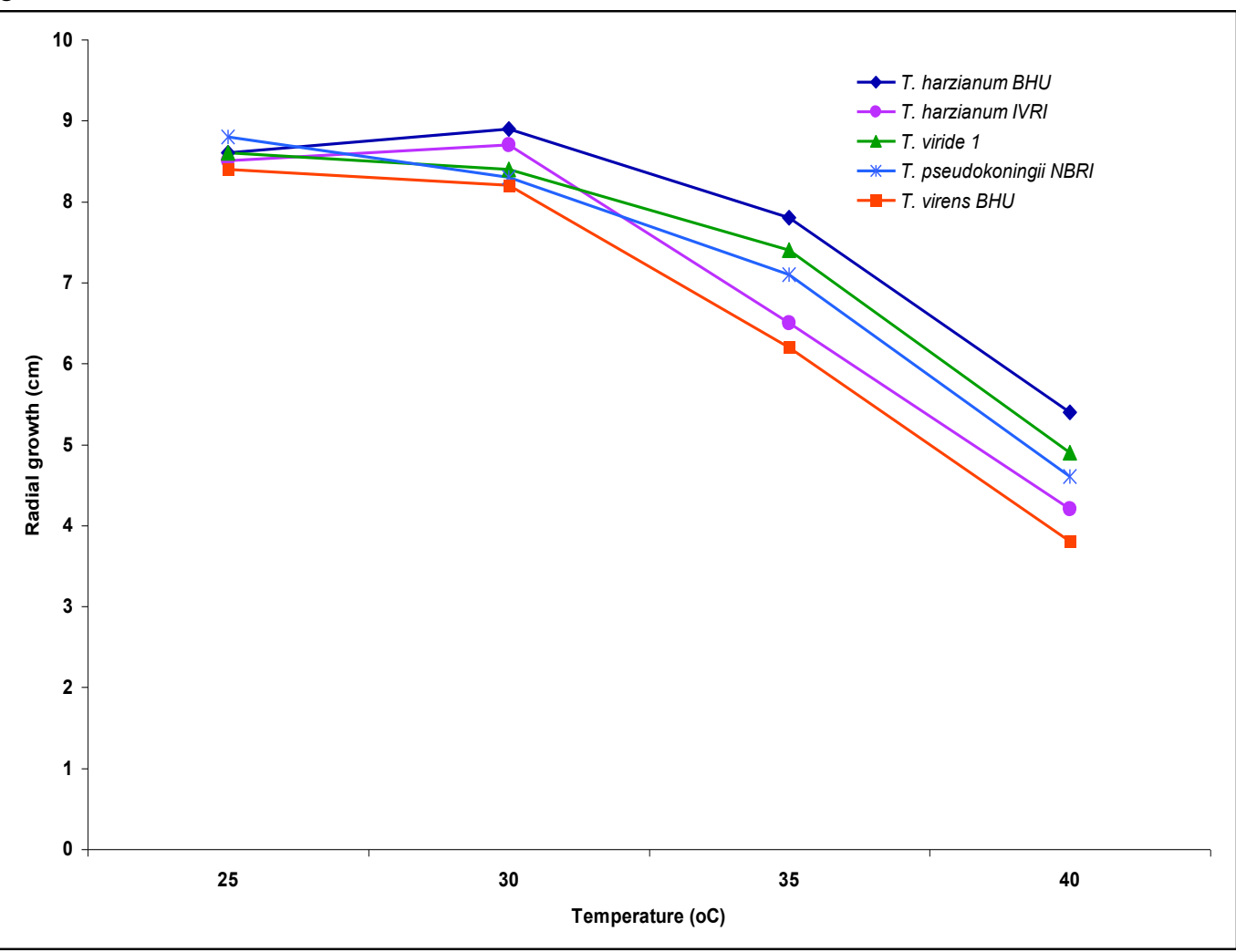

Figure 1: Effect of different temperature on growth of the selected Trichoderma species 


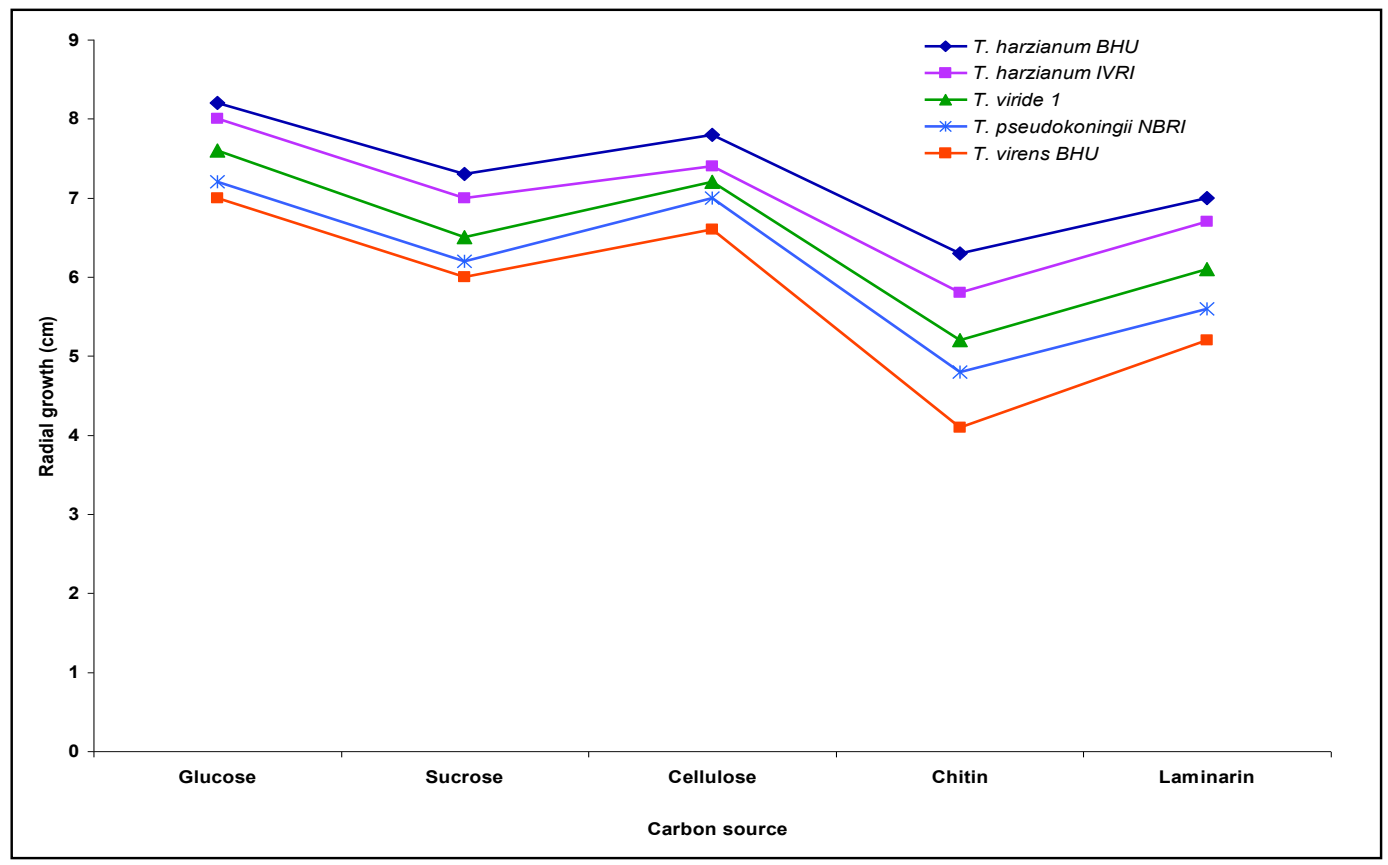

Figure 2: Effect of different $\mathrm{pH}$ on growth of the selected Trichoderma species

Table 1: Effect of different temperature $\left({ }^{\circ} \mathrm{C}\right)$ on the sporulation of selected Trichoderma species

\begin{tabular}{|c|c|c|c|c|}
\hline \multirow{2}{*}{ Trichoderma species } & $\mathbf{2 5}$ & $\mathbf{3 0}$ & $\mathbf{3 5}$ & $\mathbf{4 0}$ \\
\cline { 2 - 5 } & \multicolumn{4}{|c|}{ Spores $\times \mathbf{1 0}$ per ml of culture } \\
\hline T. harzianum BHU & $296 \pm 2.0$ & $329 \pm 2.1$ & $261 \pm 1.1$ & $240 \pm 4.0$ \\
\hline T. harzianum IVRI & $242 \pm 2.1$ & $284 \pm 2.0$ & $225 \pm 1.1$ & $208 \pm 4.0$ \\
\hline T. viride 1 & $219 \pm 4.1$ & $198 \pm 4.0$ & $157 \pm 3.1$ & $134 \pm 3.1$ \\
\hline T. pseudokoningii NBRI & $239 \pm 4.1$ & $215 \pm 4.0$ & $185 \pm 2.0$ & $144 \pm 2.1$ \\
\hline T. virens BHU & $214 \pm 3.1$ & $191 \pm 2.1$ & $157 \pm 2.0$ & $133 \pm 1.1$ \\
\hline
\end{tabular}

Table 2: Effect of different pH on the sporulation of selected Trichoderma species

\begin{tabular}{|c|c|c|c|c|c|}
\hline \multirow{2}{*}{ Trichoderma species } & $\mathbf{3 . 5}$ & $\mathbf{4 . 5}$ & $\mathbf{5 . 5}$ & $\mathbf{6 . 5}$ & $\mathbf{7 . 5}$ \\
\cline { 2 - 6 } & \multicolumn{5}{|c|}{ Spores $\times \mathbf{1 0}^{\mathbf{5}}$ per $\mathbf{~ m l}$ of culture } \\
\hline T. harzianum BHU & $114 \pm 2.3$ & $231 \pm 4.5$ & $289 \pm 1.5$ & $308 \pm 3.2$ & $234 \pm 1.2$ \\
\hline T. harzianum IVRI & $108 \pm 2.2$ & $201 \pm 3.3$ & $222 \pm 2.2$ & $264 \pm 2.4$ & $198 \pm 4.4$ \\
\hline T. viride 1 & $98 \pm 4.2$ & $148 \pm 3.2$ & $184 \pm 1.2$ & $207 \pm 2.5$ & $143 \pm 1.4$ \\
\hline T. pseudokoningii NBRI & $106 \pm 4.3$ & $155 \pm 2.2$ & $195 \pm 3.3$ & $226 \pm 4.3$ & $134 \pm 2.5$ \\
\hline T. virens BHU & $93 \pm 3.5$ & $137 \pm 2.4$ & $189 \pm 2.4$ & $196 \pm 1.2$ & $123 \pm 2.5$ \\
\hline
\end{tabular}

Although different strains showed different temperature requirement for growth and sporulation, but overall, it was found that all the strains, except both the strains of Trichoderma harzianum showed medium to good growth and sporulation at temperature around $25^{\circ} \mathrm{C}$ (Table 1). The relatively narrow range of temperature permitting reproduction suggest that this phase involve some chemical and physical processes which are not necessary for vegetative growth and which are more exacting in their temperature pigment than are those which suffice for the vegetative phase (Hawker, 1966).

The $\mathrm{pH}$ of the medium greatly affected the sporulation of the Trichoderma spp. (Table 2). The optimum $\mathrm{pH}$ for all of the Trichoderma spp. was recorded 
at 6.5. Trichoderma spp. significantly differed with each other in production of spores. The result was in conformity with Jackson et al., (1991), who found that Trichoderma isolated produced optimum biomass at acidic $\mathrm{pH}$ range between 4.6 and 6.3. Das et al., (1995) also reported that Trichoderma harzianum more effectively reduce sheath blight pathogen of rice in acidic soil (PH 6.8) but it also reduces the infection in neutral soil ( $\mathrm{PH} \mathrm{7)}$ too. This acidic $\mathrm{pH}$ requirement of strain may be cause of natural good sporulating tendency of most fungi at pH range 5-6 (Lilly and Barnett, 1951).

\section{ACKNOWLEDGEMENT}

The author is thankful to Ex Prof. \& HOD, Late Dr. Bharat Rai, Department of Botany, BHU, Varanasi for valuable guidance during the course of study.

\section{REFERENCES}

Askew D.J. and Laing M.D., 1993. An adapted selective medium for the quantitative isolation of Trichoderma species. Plant Pathology, 42: 686690.

Baker R., 1986: Biological Control: An Overview. Can. J. Plant Pathol., 8:218-221.

Callan N.W., Mathre D.E. and Miller J.B., 1990. Biopriming seed treatment for biological control of Pythium ultimum preemergence damping-off in sh2 Sweet Corn. Plant Disease, 74:368- 372.

Dandurand L.M. and Knudsen G.R., 1993. Influence of Pseudomonas fluorescens on hyphal growth and biocontrol activity of Trichoderma harzianum in the spermosphere and rhizosphere of pea. Phytopathology, 83:265-270.

Das B.C, Bora L.C. and Phookan A.K., 1995. Influence of soil $\mathrm{pH}$ on Trichoderma harzianum in suppressing Sheath blight of rice. J. Agric. Sci. Soc. of North-East India, 8: 158-161.

Eastburn D.M. and Butler E.E., 1988a. Microhabitat characterization of Trichoderma harzianum in natural soil: evaluation of factors affecting population density. Soil Biol. Biochem., 20:541545.

Eastburn D.M. and Butler E.E., 1988b. Microhabitat characterization of Trichoderma harzianum in natural soil: evaluation of factors affecting distribution. Soil Biol. Biochem., 20:547-553.

El-Abyad M.S., Ismail I.K. and Al. Mashhadani S., 1983. Effects of some biocides on Fusarium oxysporum formae specials causing cotton and tomato wilt in Egypt. Trans. Br. Mycol. Soc., 80: 283-287.

Elad Y., 2000. Biological control of foliar pathogens by means of Trichoderma harzianum and potential modes of action. Crop Protect., 19: 709 - 714.

Haran S., Schikler H. and Chet I. 1996a. Molecular mechanisms of lytic enzymes involved in the biocontrol activity of Trichoderma harzianum. Microbiology, 142:2321-2331.

Haran S., Schikler H., Oppenheim A. and Chet I., 1996b. Differential Expression of Trichoderma harzianum chitinases during mycoparasitism. Phytopathology, 86:981-985.

Hawker L.E., 1966. Environmental influence on reproduction in: 'The Fungi' $2^{\text {nd }}$ Edition (Ainsworth, G.C., Sparrow, F. K. and Suss man, A.S.), Academic Press, New York.

Hermosa M.R., Grondona I., Iturriaga E.A., DíazMínguez J.M., Castro C., Monte E. and GarcíaAcha I., 2000. Molecular characterization and identification of biocontrol isolates of Trichoderma spp. Appl. Environ. Microbiol., 66:1890-1898.

Henis Y., 1984. Biological control. In Current Perspectives in Microbial Ecology, Klug, M.J., Reddy, C.A. (Eds.), pp. 353-361, American Society of Microbiology, Washington.

Hubbard J.P., Harman G.E. and Hadar Y., 1983. Effect of soilborne Pseudomonas spp. On the biological control agent, Trichoderma hamatum, on pea seeds. Phytopathology, 73:655-659.

Jackson A.M., Whipps J.M., Lynch J.M. and Bazin M.J., 1991. Biocontrol Sci. Technol., 1: 43.

Joshi B.B., Bhatt R.P. and Bahukhandi D., 2010. Antagonistic and plant growth activity of Trichoderma isolates of Western Himalayas. Environmental Biology, 31: 921-928.

Knudsen G.R. and Bin L., 1990. Effects of temperature, soil moisture, and wheat bran on growth of Trichoderma harzianum from alginate pellets. Phytopathology, 80:724-727.

Kredices L., Antal Z., Manczinger L., Szkere A., Kevei F. and Nagy E., 2003. Influence of environmental parameters on Trichoderma strains with biocontrol potential. Food Technology and Biotechnology, 41: 37-42. 
Lewis J.A. and Papavizas G.C. 1991. Biocontrol of plant diseases: the approach for tomorrow. Crop Prot., 10: 95-105.

Lilly V.G. and Barnett H.L., 1951. Physiology of the fungi. McGrew Hill Book Company N.Y., pp 464.

Mathre D.E. and Johnston R.H., 1995. Combined biological and chemical seed treatments for control of two seedling diseases of $\mathrm{Sh} 2$ sweet corn. Plant Dis., 79:1145-1148.
Papavizas G.C., 1985. Trichoderma and Gliocladium: biology, ecology and potential for biocontrol. Annu. Rev. Phytopathol., 23: 23-54.

Rifai M.A., 1969. A revision of the genus Trichoderma. Mycol. Papers., 116:1-56.

Upadhyay R.S., Visintin L. and Jayaswal R.K., 1991. Environmental factors affecting the antagonism of Pseudomonas cepacia against Trichoderma viride. Can. J. Micro-biol., 37:880-884. 